\title{
Adjuvant Tirofiban Injection Through Deployed Solitaire Stent As a Rescue Technique After failed Mechanical Thrombectomy in Acute Stroke
}

\author{
Jung Hwa Seo, MD', Hae Woong Jeong, MD², Sung Tae Kim, MD³, Eun-Gyu Kim, MD'
}

Purpose: We present our experiences of intra-arterial tirofiban injection through a deployed Solitaire stent as a rescue therapy after failed mechanical thrombectomy in patients with acute ischemic stroke.

Materials and Methods: Data on 18 patients treated with adjunctive tirofiban injection through a temporarily deployed Solitaire stent after failed mechanical thrombectomy were retrospectively reviewed. Solitaire stent was used as a primary thrombectomy device in 16 of 18 patients. Two patients received manual aspiration thrombectomy initially. If initial mechanical thrombectomy failed, tirofiban was injected intra-arterially through the deployed Solitaire stent and then subsequent Solitaire thrombectomy was performed.

Results: Fourteen patients had occlusions in the middle cerebral artery, 2 in the distal internal carotid artery, and 2 in the basilar artery. Successful recanalization was achieved in 14 patients (77.7\%) after intra-arterial injection of tirofiban and subsequent Solitaire thrombectomy. Three patients without successful recanalization after rescue method received angioplasty with stenting. Overall, successful recanalization ( $\mathrm{TICl}$ grades $2 \mathrm{~b}$ and 3 ) was achieved in 17 (94.4\%) of 18 patients. Periprocedural complications occurred in 5 patients: distal migration of emboli in 5 patients and vessel perforation in 1. Three patients died. Good functional outcome ( $\mathrm{mRS} \leq 2)$ was achieved in 9 patients $(50.0 \%)$ at 3 months.

Conclusion: Rescue intra-arterial injection of tirofiban through a temporarily deployed Solitaire stent may facilitate further recanalization in cases of failed mechanical thrombectomy in patients with acute ischemic stroke.

Key Words : Aacute; Stroke; Mechanical thrombolysis; Tirofiban; Self-expanding stent

Departments of ${ }^{1}$ Neurology, ${ }^{2}$ Diagnostic Radiology, ${ }^{3}$ Neurosurgery, Busan Paik Hospital, School of Medicine, Inje University, Busan, Korea Received February 13, 2015; accepted after revision February 20, 2015.

Correspondence to: Hae Woong Jeong, MD, Department of Diagnostic Radiology, Busan Paik Hosipital, Inje University College of Medicine, 75 Bokji-ro, Busanjin-gu, Busan 614-735, Korea.

Tel. 82.51.890.6547 Fax. 82.51.896.1085 E-mail: hwjeong2000@lycos.co.kr

This is an Open Access article distributed under the terms of the Creative Commons Attribution Non-Commercial License (http://creativecommons.org/licenses/by-nc/3.0) which permits unrestricted non-commercial use, distribution, and reproduction in any medium, provided the original work is properly cited. 
Although intravenous (IV) recombinant tissue plasminogen activator (rt-PA) is still the first line treatment in acute ischemic stroke up to 4.5 hour time window, endovascular treatment might be superior to IV-rtPA alone to achieve revascularization in cases of large vessel occlusions. Among the several available devices for mechanical thrombectomy, mechanical thrombectomy using Solitaire stent (Covidien/ev3, Dublin, Ireland) has demonstrated high efficacy for successful recanalization of large artery occlusion in acute ischemic stroke $[1,2]$. However, failure of mechanical thrombectomy to achieve successful revascularization has been reported in $20-30 \%$ of treated cases. In cases resistant to mechanical thrombectomy, several techniques have been introduced as a rescue method including the use of other stent retrievers, intraarterial thrombolysis, stent implantation [3], balloon angioplasty [4] and double Solitaire mechanical thrombectomy [5]. Here, we present our experiences of another rescue technique in which adjunctive tirofiban was injected through temporarily deployed Solitaire stent after failure of initial mechanical thrombectomy. We evaluated the feasibility, safety, and angiographic and clinical results of this technique.

\section{MATERIALS AND METHODS}

\section{Patients}

In this retrospective study, a consecutive series of patients was identified from stroke database of our hospital. From March 2013 to October 2014, we collected patients treated with adjunctive tirofiban injection during solitaire stent deployment after failure of initial trial of mechanical thrombectomy using Solitaire stent. During study period, a total of 96 mechanical thrombectomy procedures for large artery occlusions were performed at our hospital. Among them, 18 patients received adjunctive tirofiban injection during mechanical thrombectomy using Solitaire stent.

Prior to mechanical thrombectomy, CT and MRI were performed to evaluate the salvageable brain tissues and the presence of absence of intracranial hemorrhage. All patients underwent diffusion, perfusion imaging, and CT or MR angiography. When no other contraindications existed, a bridging IV-rtPA treatment was initiated after imaging study.

The indications for endovascular therapy were as following: 1) clinical diagnosis of acute stroke; 2) baseline National Institute of Health Stroke Scale (NIHSS) score $>4 ; 3$ ) intracranial large artery occlusion; 4) definite diffusion-perfusion or diffusion- clinical mismatch, 5) no intracranial hemorrhage.

\section{Mechanical thrombectomy procedures}

All procedures were performed under local anesthesia with/without sedative agents. A 6F Envoy guiding catheter (Codman, Raynham, MA) into a shuttle catheter (Cook Medical Inc., Bloomington, IN) or 9F Optimo balloon tipped guiding catheter (Tokai Medical Products, Aichi, Japan) was coaxially placed in the proximal extracranial vessel. The guiding catheter was continuously flushed with heparinized saline.

A Prowler select plus catheter (Codman \& Shurtleff, Inc., Raynham, Massachusetts) with a Synchro 0.014 microguidewire (Stryker, Fremont, California) was navigated distal to the thrombus. Then Solitaire stent was deployed across the clot. The stent was kept deployed for 5 or 10 minutes before retrieving it. The partial re-sheathed Solitaire stent and the delivery microcatheter were gently withdrawn through the guiding catheter. While retrieving, proximal aspiration with a $50 \mathrm{cc}$ syringe was performed through the guiding catheter. Immediate follow-up cerebral angiography was performed to assess recanalization. When one or more attempts of mechanical thrombectomy using Solitaire stent were failed, adjuvant injection of tirofiban through deployed Solitaire stent as a rescue method. Adjuvant tirofiban was injected $0.1 \mathrm{mg}$ per a minute through microcatheter holding Solitaire stent. Then Solitaire stent and delivery microcatheter was withdrawn. Failure of initial thrombectomy was determined by individual operator's discretion. Example of the procedure is presented in figure 1. If successful recanalization did not occur, Solitaire thrombectomy was repeated according to operator's discretion.

\section{Outcome measures and follow-up}

The target vessel recanalization was assessed in the cerebral angiography and classified by using TICI score. Neurological improvement was assessed using NIHSS score at day 7. Neurological improvement was defined as improvement of NIHSS score more than 4 points. Functional outcome was assessed by $\mathrm{mRS}$ score at day 90. All patients underwent CT scan immediately after the procedure to evaluate hemorrhagic complications. Diffusion imaging and CT or MR angiography were performed within 24 hours and 7 days after thrombectomy. Complications associated with mechanical thrombectomy procedures including distal migration of emboli and post-procedural hemorrhage were investigated. 


\section{Jung Hwa Seo, et al.}

\section{RESULTS}

Baseline characteristics, procedures, and clinical outcomes are shown in Table 1. Median age and initial NIHSS score was 67 years (range, 50-92) and 15 (range, 6-29). Mean time of first found abnormal time was 233 minutes. Fourteen patients had occlusions in the middle cerebral artery, 2 in the distal internal carotid artery, and 2 in the basilar artery. Four patients were treated with IV rt-PA before the mechanical thrombectomy.
In 16 of 18 patients, Solitaire stent was used as first line device for mechanical thrombectomy. Manual aspiration thrombectomy with Penumbra reperfusion catheter was performed prior to Solitaire thrombectomy in 2 patients. Two patients received emergent carotid artery stenting prior to intracranial recanalization therapy for treatment of occlusion of cervical ICA. The mean dose of tirofiban used was $0.33 \mathrm{mg}$ (range, 0.2$0.75 \mathrm{mg}$ ).

Successful recanalization was achieved in 14 (77.7\%) of 18 patients after intraarterial injection of tirofiban and subsequent Solitaire thrombectomy. Three
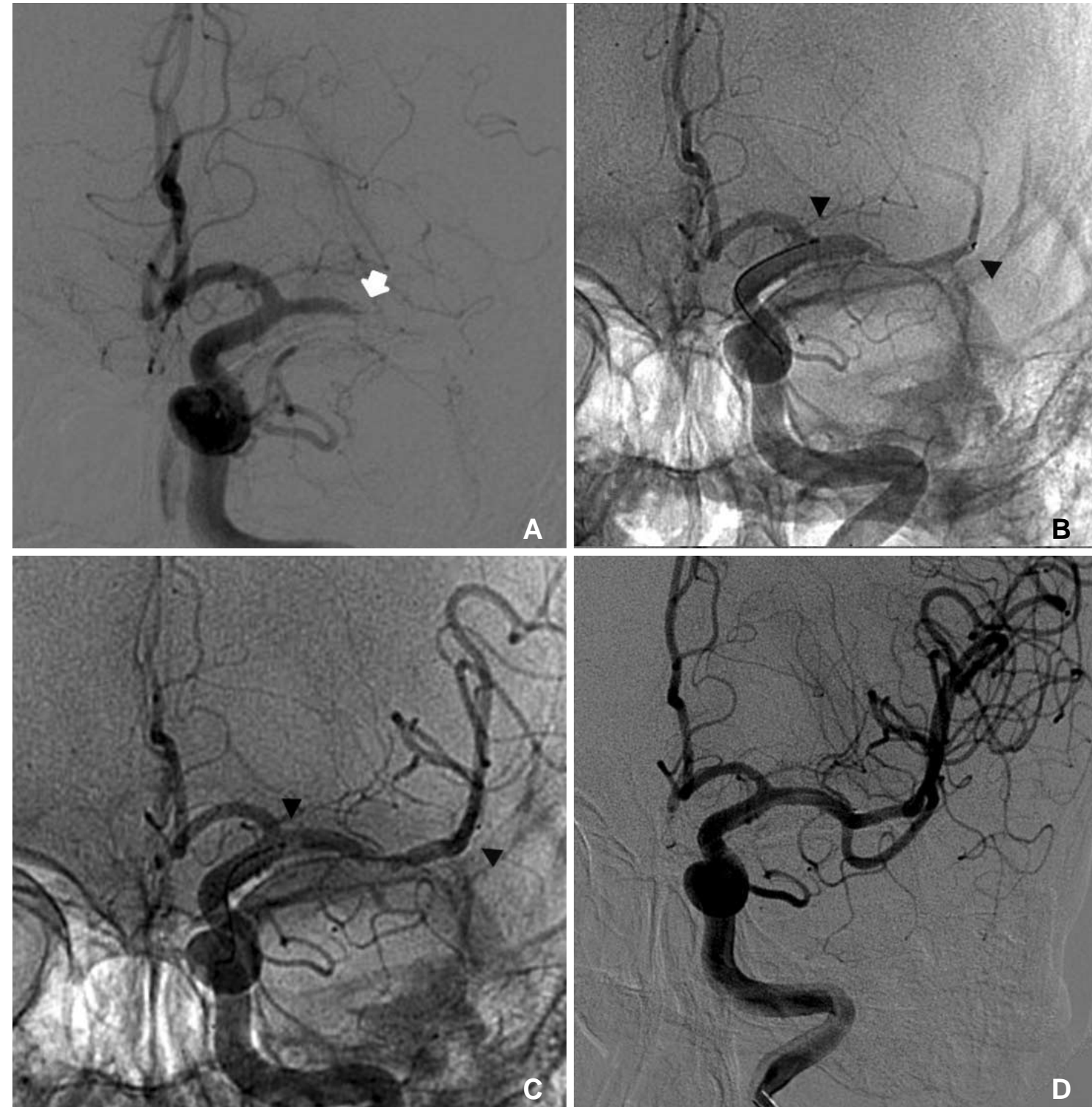

Fig. 1. Adjuvant tirofiban injection through a deployed solitaire stent in a patient with acute MCA occlusion. A. Cerebral angiography showed complete occlusion of the left MCA (white arrow). Two attempts with mechanical thrombectomy using Solitaire stent (black arrow) failed. B. Third mechanical thrombectomy using Solitaire stent was attempted. C. After injection of $0.5 \mathrm{mg}$ of tirofiban for $5 \mathrm{minutes}$ through a deployed Solitaire stent, angiogram shows increased blood flow through the occluded segment. Then, the Solitaire stent was retrieved. D. Final angiogram shows successful recanalization of the occluded left MCA. 


\section{Tirofiban Injection in Solitaire Thrombectomy}

patients without successful recanalization received balloon angioplasty with a Gateway balloon catheter (Boston Scientific, Fremont, California) and stenting with a Wingspan stent (Boston Scientific, Fremont, California) and achieved successful recanalization.
Thus, overall successful recanalization was achieved in $17(94.4 \%)$ of 18 patients. Before injection of intraarterial tirofiban, the mean number of passage of Solitaire stent was 1.9 (range, 1-3). After tirofiban injection, the number of passage of Solitaire stent to

Table. Characteristics, Procedural Results and Clinical Outcomes of 18 Patients

\begin{tabular}{|c|c|c|c|c|c|c|c|c|c|c|c|c|}
\hline No. & $\begin{array}{l}\text { Sex/ } \\
\text { Age }\end{array}$ & $\begin{array}{l}\text { IV } \\
\text { tPA }\end{array}$ & $\begin{array}{l}\text { FAT, } \\
\text { minutes }\end{array}$ & $\begin{array}{l}\text { Occlusion } \\
\text { site }\end{array}$ & $\begin{array}{l}\text { Initial } \\
\text { NIHSS }\end{array}$ & $\begin{array}{l}\text { Risk } \\
\text { factors }\end{array}$ & $\begin{array}{l}\text { Total number } \\
\text { of pass } \\
\text { (Pre-/Post- } \\
\text { tirofiban) }\end{array}$ & $\begin{array}{c}\text { Tirofiban } \\
\text { dose }\end{array}$ & $\mathrm{TICl}$ & $\begin{array}{l}\text { 7-day } \\
\text { NIHSS }\end{array}$ & $\begin{array}{l}\text { 3-month } \\
\text { mRS }\end{array}$ & Complication \\
\hline 1 & $F / 66$ & Yes & 156 & Rt. M2 & 14 & HTN, cancer & $3(2 / 1)$ & $0.75 \mathrm{mg}$ & 3 & 0 & 0 & - \\
\hline 2 & $\mathrm{M} / 50$ & No & 34 & Lt. M1 & 20 & $\begin{array}{l}\text { HCMP, newly } \\
\text { Afib, old ICH }\end{array}$ & $3(2 / 1)$ & $0.5 \mathrm{mg}$ & 3 & 5 & 2 & $\begin{array}{c}\text { Distal } \\
\text { embolism }\end{array}$ \\
\hline 3 & $\mathrm{M} / 71$ & No & 70 & Rt. T-ICA & 18 & HTN, Smoker & $2(1 / 1)$ & $0.2 \mathrm{mg}$ & 3 & 14 & 3 & $\begin{array}{c}\text { Petechial } \\
\text { hemorrhage }\end{array}$ \\
\hline 4 & $\mathrm{M} / 65$ & Yes & 43 & Lt. M2 & 13 & $\begin{array}{l}\text { Afib, Smoker, } \\
\text { CAOD }\end{array}$ & $2(1 / 1)$ & $0.25 \mathrm{mg}$ & $2 b$ & 0 & 0 & - \\
\hline 5 & $\mathrm{M} / 54$ & No & 20 & Lt. M2 & 6 & $\begin{array}{l}\text { Afib, HTN, } \\
\text { Smoker }\end{array}$ & $3(2 / 1)$ & $0.25 \mathrm{mg}$ & $2 b$ & 2 & 0 & - \\
\hline 6 & $F / 66$ & Yes & 123 & BA & 8 & HTN, DM, Afib & $3(2 / 1)$ & $0.2 \mathrm{mg}$ & 3 & 21 & 6 & - \\
\hline 7 & $\mathrm{~F} / 82$ & No & 113 & Rt. M1 & 15 & $\begin{array}{l}\text { Afib, CAOD, } \\
\text { old CVA }\end{array}$ & $4(3 / 1)$ & $0.4 \mathrm{mg}$ & $0^{*}$ & 15 & 4 & $\begin{array}{c}\text { Petechial } \\
\text { hemorrhage }\end{array}$ \\
\hline 8 & $\mathrm{M} / 54$ & No & 87 & BA & 14 & HTN, Smoker & $3(2 / 1)$ & $0.2 \mathrm{mg}$ & $1^{*}$ & 2 & 1 & - \\
\hline 9 & $\mathrm{~F} / 87$ & No & 61 & M1 & 14 & $\begin{array}{l}\text { DM, HTN, } \\
\text { old CVA }\end{array}$ & $3(1 / 2)$ & $0.4 \mathrm{mg} \times 2$ & $2 b$ & 7 & 4 & $\begin{array}{c}\text { Distal } \\
\text { embolism }\end{array}$ \\
\hline 10 & $\mathrm{M} / 77$ & No & 70 & Lt. M1 & 18 & $\begin{array}{c}\text { Afib, DVT, ASO, } \\
\text { Smoker, ICH }\end{array}$ & $4(3 / 1)$ & $0.3 \mathrm{mg}$ & $2 b$ & 14 & 5 & $\begin{array}{c}\text { Petechial } \\
\text { hemorrhage }\end{array}$ \\
\hline 11 & $\mathrm{M} / 80$ & No & 85 & Lt. M1 & 19 & $\begin{array}{l}\mathrm{HF}, \mathrm{CAOD}, \\
\text { old CVA }\end{array}$ & $3(2 / 1)$ & $0.3 \mathrm{mg}$ & 3 & Expired & 6 & $\begin{array}{c}\mathrm{ICH}, \\
\text { distal emboli, } \\
\text { Wire } \\
\text { perforation }\end{array}$ \\
\hline 12 & M/55 & No & 210 & Rt. M1 & 15 & - & $4(3 / 1)$ & $0.2 \mathrm{mg}$ & $0^{*}$ & 8 & 2 & $\begin{array}{l}\text { Asymtomatic } \\
\mathrm{ICH}\end{array}$ \\
\hline 13 & $\mathrm{M} / 64$ & No & 40 & Lt. M1 & 13 & Cancer, DM & $2(1 / 1)$ & $0.3 \mathrm{mg}$ & $2 b$ & 10 & 5 & - \\
\hline 14 & $\mathrm{M} / 61$ & No & 30 & Lt. M1 & 15 & - & $4(3 / 1)$ & $0.3 \mathrm{mg}$ & $2 b$ & 6 & 1 & Distal embolism \\
\hline 15 & $\mathrm{~F} / 87$ & Yes & 94 & Lt. T-ICA & 20 & Afib & $3(2 / 1)$ & $0.3 \mathrm{mg}$ & $2 b$ & 3 & 6 & $\begin{array}{c}\text { Petechial } \\
\text { hemorrhage }\end{array}$ \\
\hline 16 & $\mathrm{M} / 39$ & No & 490 & Lt. M1 & 17 & HTN & $2(1 / 1)$ & $0.25 \mathrm{mg}$ & $2 b$ & 6 & 2 & Distal embolism \\
\hline 17 & $\mathrm{M} / 53$ & No & 480 & Lt. M1 & 10 & AVR, Smoker & $3(2 / 1)$ & $0.55 \mathrm{mg}$ & $2 a$ & 6 & 2 & - \\
\hline 18 & $\mathrm{M} / 92$ & No & 250 & Rt. M1 & 29 & HTN, Smoker & $2(1 / 1)$ & $0.3 \mathrm{mg}$ & $2 b$ & 29 & 5 & - \\
\hline
\end{tabular}

Abbreviations: IV tPA, intravenous recombinant tissue plasminogen activator; FAT, first found abnormal time; NIHSS, the National Institute of Health Scale Score; mRS, modified Rankin score; M1 and M2, middle cerebral artery segment; T-ICA, distal ICA to ACA and MCA; BA, Basilar artery; HTN, hypertension; DM, Diabetes mellitus; Afib, atrial fibrillation; CAOD, coronary artery occlusive disease; ICH, intracranial hemorrhage; CVA, cerebrovascular accident; DVT, deep vein thrombosis; ASO, arteriosclerotic obliterans; AVR, aortic valve regurgitation

*: additional angioplasty with stent insertion was performed to achieve successful recanalization. 


\section{Jung Hwa Seo, et al.}

achieve successful recanalization was one.

Neurological improvement (decrease of NIHSS score more than 4 points) at 7 days was observed in 13 patients $(72.2 \%)$. Good functional outcome $(\mathrm{mRS} \leq 2)$ was observed in 9 patients $(50.0 \%)$ at 3 months. Periprocedural complications occurred in 5 patients (5 distal migration of emboli and 1 vessel perforation). One patient with vessel perforation by microguidewire died of massive intracranial hemorrhage the day after the procedure. Overall, the mortality rate was $16.6 \%$ $(3 / 18)$. Other fatalities were not directly related thrombectomy procedure. The one fatality was caused by malignant edema following large cerebellar infarction despite of successful recanalization of basilar artery. The other one was due to recurrent stroke.

\section{DISCUSSION}

In our case series, intra-arterial injection of tirofiban through a temporarily deployed Solitaire stent was promising because it is simple and has ability to achieve a high rate $(77.7 \%)$ of recanalization in refractory cases. Good outcome rate $(50 \%)$ in this study was comparable with those of randomized clinical trials of mechanical thrombectomy with Solitaire stent $[1,2]$.

The Solitaire stent is a self-expanding stent retriever designed to restore blood flow in patients with ischemic stroke due to large intracranial vessel occlusion and has yielded high rates of reperfusion and favorable clinical outcomes in patients with acute ischemic stroke [1,68]. Despite higher recanalization rates of $61-85 \%$ [1, 2 , $4,8]$, not a few patients are still left without sufficient recanalization after mechanical thromectomy using Solitaire stent. Several different techniques to treat refractory cases to mechanical thrombectomy using stent retriever have been previously introduced. One case series showed that balloon angioplasty is an effective procedure when recanalization failed with Solitaire stent alone [4]. In study of Kurre el al. [3], other rescue methods were applied including the use of different stent retrievers, balloon angioplasty, permanent implantation of a stent, distal aspiration without a retriever and intra-arterial fibrinolysis. Klisch el al. [5] recently reported a $80 \%$ of successful recanalization and $50 \%$ of good clinical outcome in patients who had rescue treatment with double Solitaire stent retriever technique.

Tirofiban is a fast-acting, fast-deactivated, highly selective glycoprotein IIb/IIIa antagonists approved by Food and Drug Administration for the treatment of acute coronary syndrome up to 48 hours after onset.9
Tirofiban block the fibrin-binding receptors reversibly and effectively to prevent platelet aggregation. In the Safety of Tirofiban in acute Ischemic Stroke (SaTIS) trial, tirofiban is safe in acute moderate ischemic stroke even when administered within 3 to 22 hours after symptom onset and might save lives in the late outcome [10].

The benefits and risks of glycoprotein-IIb/IIIa inhibitor in patients receiving mechanical thrombectomy for acute stroke have been reported. Several case series showed that tirofiban was not associated with a significantly increased cerebral bleeding rate in patients with acute ischemic stroke [11-13]. However, in a recent observational study, patients who received tirofiban during mechanical thrombectomy for acute ischemic stroke had a higher risk of fatal intracerebral hemorrhage and poor outcome [14]. These findings should raise great caution in the use of tirofiban during mechanical thrombectomy for acute ischemic stroke. However, in latter study, tirofiban was infused via intravenous route continuously at least 12 hours after the intervention [14]. In our study, low-dose of tirofiban was infused briefly via intra-arterial route. Intra-arterial low dose tirofiban may achieve similar effect to intravenous administration of higher dose, which may decrease the risk of bleeding complications [11].

Even though a low dose tirofiban was used in our method, the application of this rescue method should only be made after careful consideration of various individual factors, such as the time from stroke onset, size of infarction core, blood pressure, known coagulopathy or prior use of antithrombotic medication. The limitations of the study are its small sample size, single center and retrospective nature.

\section{CONCLUSION}

Intra-arterial injection of tirofiban through a temporarily deployed Solitaire stent may facilitate further mechanical recanalization in failed mechanical thrombectomy in patients with acute ischemic stroke.

\section{Disclosures}

All authors have nothing to disclosure.

\section{References}

1. Saver JL, Jahan R, Levy EI, Jovin TG, Baxter B, Nogueira RG, et al. Solitaire flow restoration device versus the Merci Retriever in patients with acute ischaemic stroke (SWIFT): a randomised, 


\section{Tirofiban Injection in Solitaire Thrombectomy}

parallel-group, non-inferiority trial. Lancet 2012;380(9849):12411249

2. Yoon YH, Yoon W, Jung MY, Yim NY, Kim BC, Kang HK. Outcome of mechanical thrombectomy with Solitaire stent as firstline intra-arterial treatment in intracranial internal carotid artery occlusion. Neuroradiology 2013;55:999-1005

3. Kurre W, Aguilar-Perez M, Schmid E, Sperber W, Bazner H, Henkes H. Clinical experience with the pREset stent retriever for the treatment of acute ischemic stroke--a review of 271 consecutive cases. Neuroradiology 2014;56:397-403

4. Park JH, Park SK, Jang KS, Jang DK, Han YM. Critical use of balloon angioplasty after recanalization failure with retrievable stent in acute cerebral artery occlusion. J Korean Neurosurg Soc 2013;53:77-82

5. Klisch J, Sychra V, Strasilla C, Taschner CA, Reinhard M, Urbach $\mathrm{H}$, et al. Double solitaire mechanical thrombectomy in acute stroke: effective rescue strategy for refractory artery occlusions? AJNR Am J Neuroradiol 2014

6. Mpotsaris A, Bussmeyer M, Loehr C, Oelerich M, Buchner H, Weber W. Mechanical thrombectomy in severe acute stroke: preliminary results of the Solitaire stent. J Neurol Neurosurg Psychiatry 2012;83:117-118

7. Castano C, Dorado L, Guerrero C, Millan M, Gomis M, Perez de la Ossa N, et al. Mechanical thrombectomy with the Solitaire AB device in large artery occlusions of the anterior circulation: a pilot study. Stroke 2010;41:1836-1840

8. Miteff F, Faulder KC, Goh AC, Steinfort BS, Sue C, Harrington
TJ. Mechanical thrombectomy with a self-expanding retrievable intracranial stent (Solitaire AB): experience in 26 patients with acute cerebral artery occlusion. AJNR Am J Neuroradiol 2011;32: 1078-1081

9. Inhibition of the platelet glycoprotein IIb/IIIa receptor with tirofiban in unstable angina and non-Q-wave myocardial infarction. Platelet Receptor Inhibition in Ischemic Syndrome Management in Patients Limited by Unstable Signs and Symptoms (PRISM-PLUS) Study Investigators. N Engl J Med 1998;338:1488-1497

10. Siebler M, Hennerici MG, Schneider D, von Reutern GM, Seitz RJ, Rother J, et al. Safety of Tirofiban in acute Ischemic Stroke: the SaTIS trial. Stroke 2011;42:2388-2392

11. Baik SK, Oh SJ, Park KP, Lee JH. Intra-arterial tirofiban infusion for partial recanalization with stagnant flow in hyperacute cerebral ischemic stroke. Interv Neuroradiol 2011;17:442-451

12. Junghans U, Seitz RJ, Aulich A, Freund HJ, Siebler M. Bleeding risk of tirofiban, a nonpeptide GPIIb/IIIa platelet receptor antagonist in progressive stroke: an open pilot study. Cerebrovasc Dis 2001; 12:308-312

13. Song TJ, Lee KO, Kim DJ, Lee KY. Rescue treatment with intraarterial tirofiban infusion and emergent carotid stenting. Yonsei Med J 2008;49:857-859

14. Kellert L, Hametner C, Rohde S, Bendszus M, Hacke W, Ringleb $\mathrm{P}$, et al. Endovascular stroke therapy: tirofiban is associated with risk of fatal intracerebral hemorrhage and poor outcome. Stroke 2013;44:1453-1455 